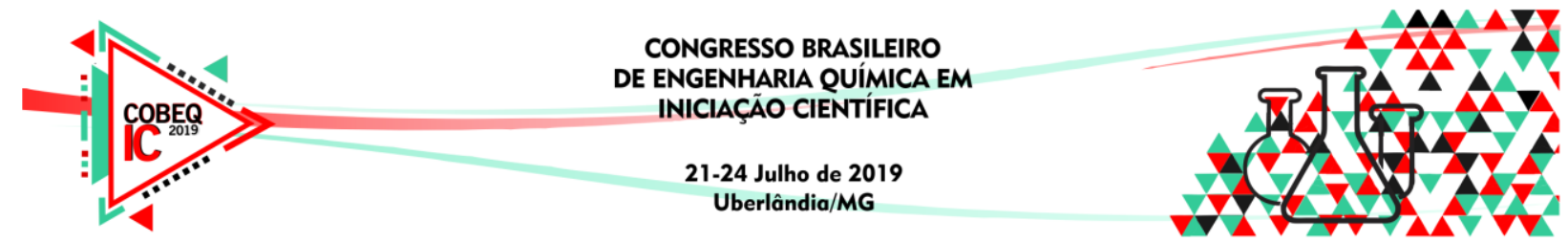

\title{
ESTUDO DE PRÉ-TRATAMENTOS PARA DISPONIBILIZAÇÃO DE AÇÚCARES REDUTORES A PARTIR DO BAGAÇO DE CANA-DE-AÇÚCAR
}

\author{
J. F. RESENDE ${ }^{1}$, K. I. M. SOUZA ${ }^{1}$, L. T. MONGELLI ${ }^{1}$ e L. F. MAIA ${ }^{1}$ \\ ${ }^{1}$ Centro Universitário da Fundação Educacional de Barretos, Departamento de Engenharia \\ Química \\ E-mail para contato: jayana.freitas@ hotmail.com
}

\begin{abstract}
RESUMO - A biomassa lignocelulósica vem sendo considerada um biocombustível em potencial para obtenção do etanol de segunda geração, o grande desafio é desenvolver a melhor opção que disponibilize a glicose a partir da hidrólise da celulose considerando a viabilidade econômica, rendimento glicosídico e fermentabilidade do material hidrolisado. $\mathrm{O}$ objetivo desse trabalho foi identificar os melhores parâmetros para o pré-tratamento e hidrólise da celulose. Foram abordados três pré-tratamentos para a comparação e em seguida a hidrólise ácida, sendo os pré-tratamentos: ácido, alcalino e hidrotérmico. Para o delineamento experimental o pré-tratamento ácido foi realizado com ácido sulfúrico 7 e 9\% (v/v), o pré-tratamento alcalino com hidróxido de sódio 4 e $7 \%(\mathrm{~m} / \mathrm{v})$, o pré-tratamento hidrotérmico com água destilada, e a hidrólise realizada com ácido sulfúrico $72 \%(\mathrm{v} / \mathrm{v})$. No pré-tratamento a biomassa teve tempo de autoclavagem de 30, 45 e 60 minutos, enquanto na hidrólise permaneceu em autoclave durante 30 minutos, ambos submetidos a temperatura/pressão de $121^{\circ} \mathrm{C}$ a 1 atm. Subsequente aos experimentos foi realizada determinação de açúcares redutores para obter a concentração dos mesmos em cada teste, apresentando como melhor o pré-tratamento alcalino de $4 \%$ e tempo de 45 minutos, sendo coerente com a literatura.
\end{abstract}

\section{INTRODUÇÃO}

A necessidade na substituição do combustível fóssil por biocombustíveis vem sendo inevitável. O menor consumo de combustível fóssil gera a diminuição da emissão de gases ligados ao efeito estufa e aquecimento global. Além da sustentabilidade e do desafio da viabilidade econômica, substituir esse combustível é uma alternativa para a considerável restrição de petróleo no futuro. Sendo assim alguns países estão optando por utilizarem combustíveis alternativos como os biocombustíveis, empenhando-se em projetos para produzir combustíveis líquidos, tais como o etanol produzido pela fermentação de açúcares extraídos (etanol de primeira geração) da cana-de-açúcar, do milho, da beterraba, entre outras fontes (OGEDA; PETRI, 2010).

Segundo Ogeda e Petri (2010), outro método para a produção do etanol é a partir das biomassas lignocelulósicas, como bagaço e palha da cana-de-açúcar, a palha de trigo, a palha de arroz, a casca de café, entre outras, geralmente encontradas em grandes quantidades nas plantações industriais. Basicamente, esse método envolve a quebra da parede celular do material lignocelulósico através de tratamentos, que podem ser feitos por meio de enzimas ou 


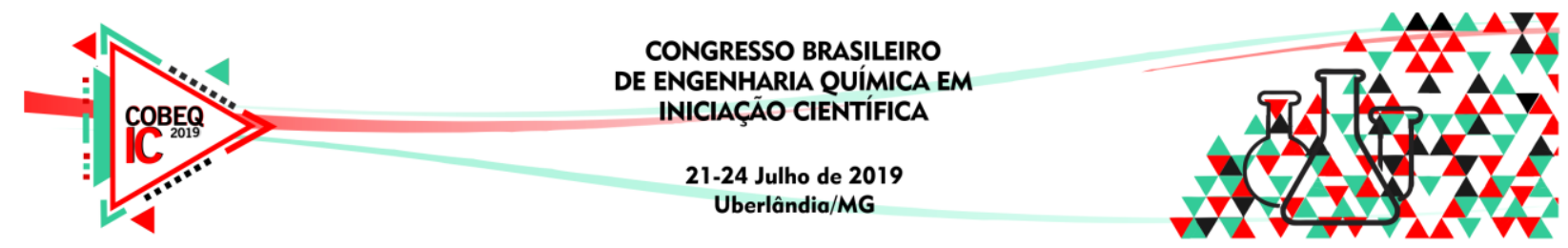

solventes, expondo assim a celulose e hemicelulose para o processo de hidrólise e obtenção de etanol.

\section{METODOLOGIA}

\subsection{Preparo do bagaço de cana}

Pesou-se $200 \mathrm{~g}$ de bagaço de cana e adicionou-se quatro litros água destilada, levando a mistura para aquecimento em banho-maria a $70^{\circ} \mathrm{C}$ por uma hora com agitação em intervalos de 10 minutos. Em seguida o material foi filtrado em peneira comum de nylon e lavado com um litro de água destilada.

$\mathrm{O}$ aquecimento e a lavagem foram realizados três vezes com o objetivo de eliminar resíduos de terra, cinzas, açúcar residual e outros glicídios hidrossolúveis com massa molecular baixa.

$\mathrm{O} \mathrm{pH}$ da água de lavagem foi verificado para ter-se o conhecimento sobre a acidez da matéria-prima.

Todo o bagaço foi levado para a estufa a $60^{\circ} \mathrm{C}$ por 24 horas, após seco o material foi submetido a moagem em um moinho de facas contínuo e peneirado, para ajuste da granulometria com peneira da série Tyler.

\subsection{Pré-tratamentos}

Realizou-se três diferentes pré-tratamentos: ácido, alcalino e hidrotérmico, com tempo de autoclavagem de 30, 45, e 60 minutos, sendo submetidos a mesma temperatura e pressão de $121^{\circ} \mathrm{C}$ e $1 \mathrm{~atm}$. Todos os experimentos foram realizados com amostras de $1 \mathrm{~g}$ de bagaço e em triplicatas.

\subsubsection{Pré-tratamento ácido}

O pré-tratamento ácido foi efetuado com ácido sulfúrico diluído nas concentrações de $7 \%$ e $9 \%(\mathrm{v} / \mathrm{v})$, com as amostras tendo razão de bagaço por $\mathrm{H}_{2} \mathrm{SO}_{4}$ igual a 1:20 (m/v).

Após a autoclavagem, o material foi submetido a filtragem em papel de filtro e lavagem com $200 \mathrm{~mL}$ de água destilada. Após medir o pH da solução filtrada, o mesmo foi neutralizado com solução de $\mathrm{KOH} 50 \%(\mathrm{~m} / \mathrm{v})$. O volume obtido foi vedado adequadamente e armazenado em local refrigerado para análises posteriores.

\subsubsection{Pré-tratamento alcalino}

Esse pré-tratamento foi realizado com hidróxido de sódio diluído com concentrações de $4 \%$ e $7 \%(\mathrm{v} / \mathrm{v})$, com as amostras em proporção de 1:10 (m/v).

Ao retirar da autoclave o material foi submetido a filtragem em papel filtro e lavagem com $200 \mathrm{~mL}$ de água destilada. $\mathrm{O}$ volume obtido foi vedado adequadamente e armazenado em local refrigerado para análises posteriores.

\subsubsection{Pré-tratamento hidrotérmico}

Para essa etapa a matéria-prima foi autoclavada com água destilada em proporção 1:20 (sólido-líquido). 


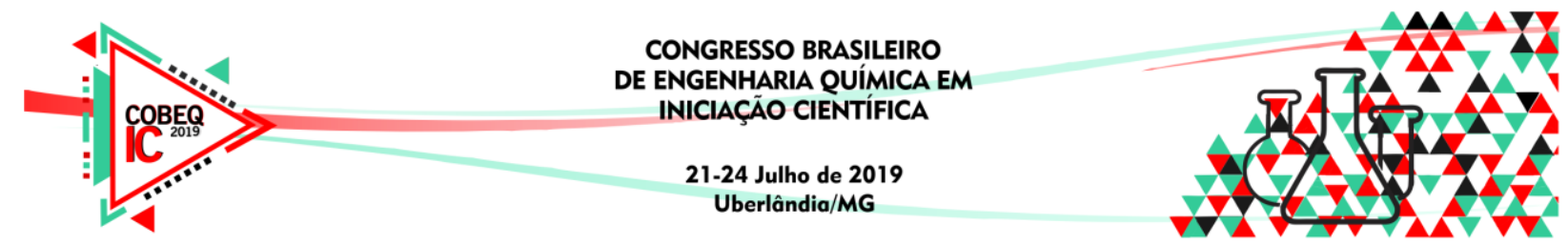

Ao retirar da autoclave o material foi submetido a filtragem em papel filtro e lavagem com $200 \mathrm{~mL}$ de água destilada.

\subsection{Hidrólise ácida}

Amostras de bagaço pré-tratado foram colocadas em béqueres de $100 \mathrm{~mL}$ adicionando-se $5 \mathrm{~mL}$ de $\mathrm{H}_{2} \mathrm{SO}_{4} 72 \%$ (v/v) em banho-maria a $45^{\circ} \mathrm{C}$ por 7 minutos. Posteriormente as amostras foram transferidas para erlenmeyers de $500 \mathrm{~mL}$ adicionando-se $140 \mathrm{~mL}$ de água destilada. Os elernmeyers foram lacrados e levados para a autoclave a $121^{\circ} \mathrm{C}$ por 30 minutos. Após a autoclavagem as amostras foram filtradas e a acidez dessas amostras foram medidas para que fosse realizada a neutralização do $\mathrm{pH}$.

A regulagem do $\mathrm{pH}$ foi efetuada com solução de hidróxido de potássio $50 \%(\mathrm{~m} / \mathrm{v})$.

A fração líquida foi armazenada na geladeira para futuramente efetuar análise de quantificação de açúcares redutores.

A fração sólida retida no papel de filtro foi descartada.

Na figura 1 temos a representação das etapas do processo empregadas na metodologia.

Figura 1. Fluxograma das etapas empregadas.

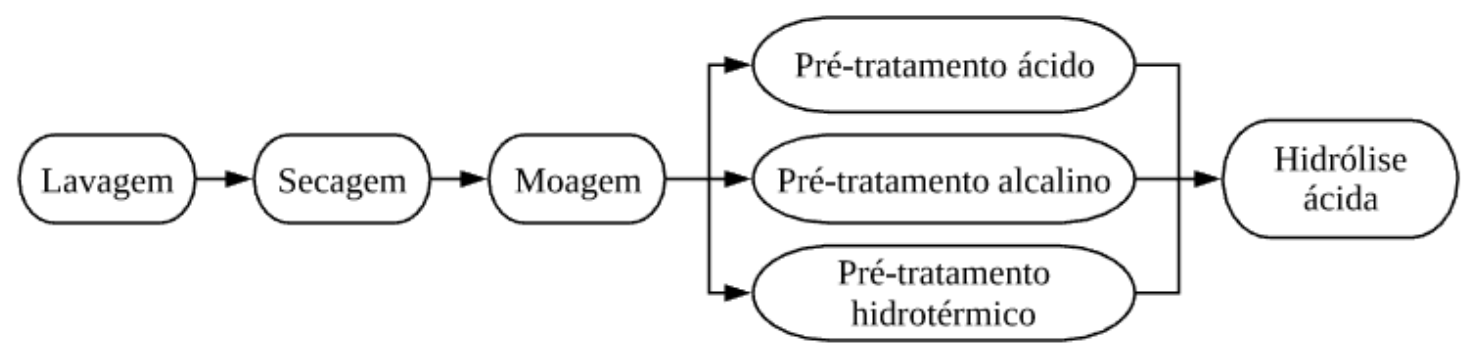

\subsection{Análises}

\subsubsection{Teor de umidade do bagaço de cana}

Para a determinação de umidade da matéria-prima foi utilizado o método de secagem na estufa. Pesou-se um cadinho seco, que foi previamente tarado, em seguida adicionou-se $2 \mathrm{~g}$ de bagaço de cana levando a amostra para a estufa a $105^{\circ} \mathrm{C}$ por 24 horas. Feito isso retirou-se a amostra, levando-a a um dessecador até resfriar. Pesou-se novamente para efetuar o cálculo da porcentagem de umidade do bagaço de cana pela equação (1).

$$
\% \text { Umidade }=\frac{100 n}{P_{\alpha}}
$$

Sendo,

$\mathrm{n}$ : peso em $\mathrm{g}$ de umidade $=$ Peso inicial $(\mathrm{g})-$ Peso final $(\mathrm{g})$

Pa: peso da amostra 


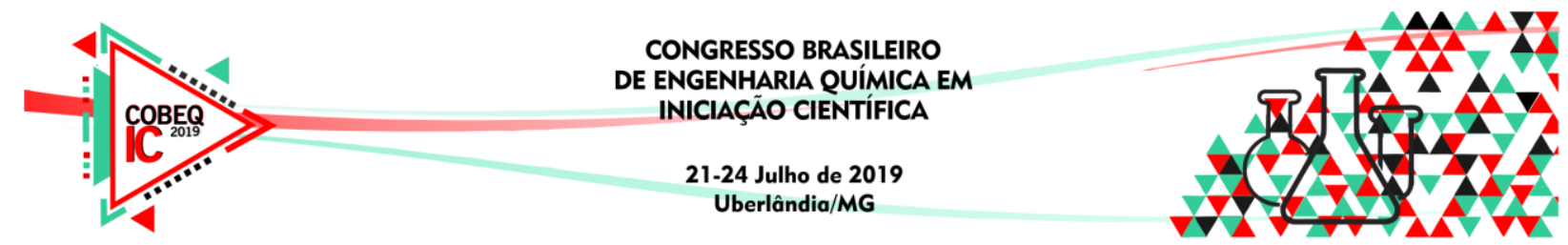

2.4.2. Quantificação de açúcares redutores

A fração líquida obtida a partir dos pré-tratamentos e hidrólise foi utilizada para determinar os açúcares redutores conforme a metodologia de Somogyi, adaptado por Nelson (1994).

\section{RESULTADOS E DISCUSSÃO}

O bagaço teve granulometria ajustada para aproximadamente $0,250 \mathrm{~mm}$, e os valores obtidos de $\mathrm{pH}$ e umidade foram de 4,39 e $51,5 \%$ respectivamente.

\subsection{Quantificação de açúcares}

Para a análise do teor de açúcares redutores, foi realizado por espectrofotometria o método de Somogyi adaptado por Nelson.

Inicialmente construiu-se uma curva de calibração de glicose, tendo como base a lei de Lambert-Beer, para relacionar e comparar posteriormente com o gráfico de teor de açúcares redutores presentes nas amostras.

O gráfico de absorbância vs concentração de glicose g. $\mathrm{L}^{-1}$ está representado na figura 2, onde y representa os valores de absorbância e o x os valores de concentração de glicose g.L $L^{-1}$, gerando a equação da reta (1).

$$
y=0,3869 x+0,1659
$$

Figura 2. Curva padrão de glicose.

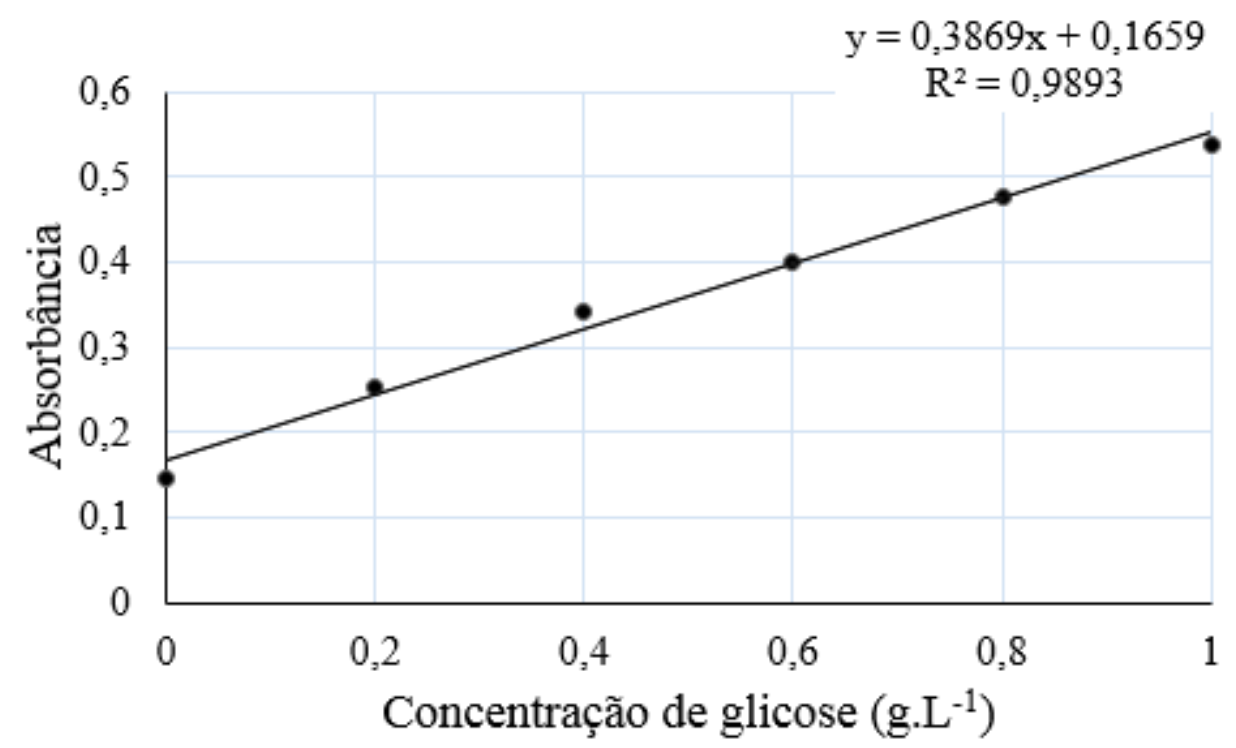

\subsection{Dados dos pré-tratamentos}




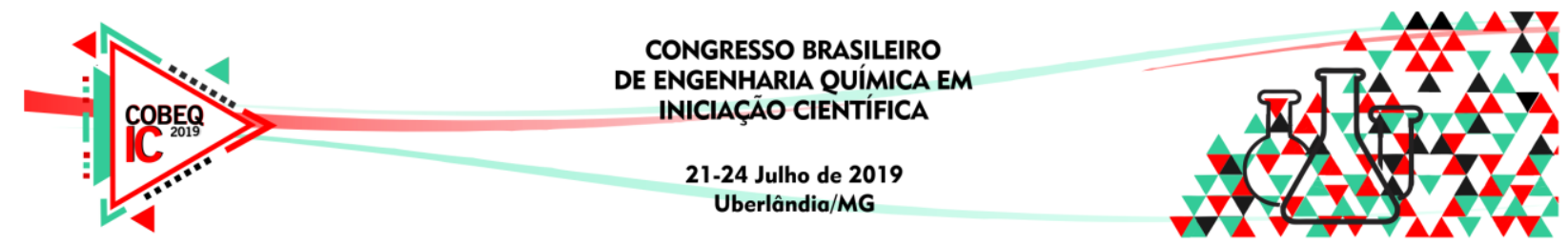

Após os experimentos, com as amostras líquidas que foram armazenadas, realizou-se as análises em espectrofotômetro para obtenção do teor de açúcares redutores. Por meio das leituras efetuadas nas análises obteve-se os valores de absorbância, a partir desses dados determinou-se os valores de concentração de açúcares redutores encontrados em cada hidrólise. Fez-se a construção do gráfico representado na figura 3.

Figura 3. Concentração de glicose após a hidrolise.

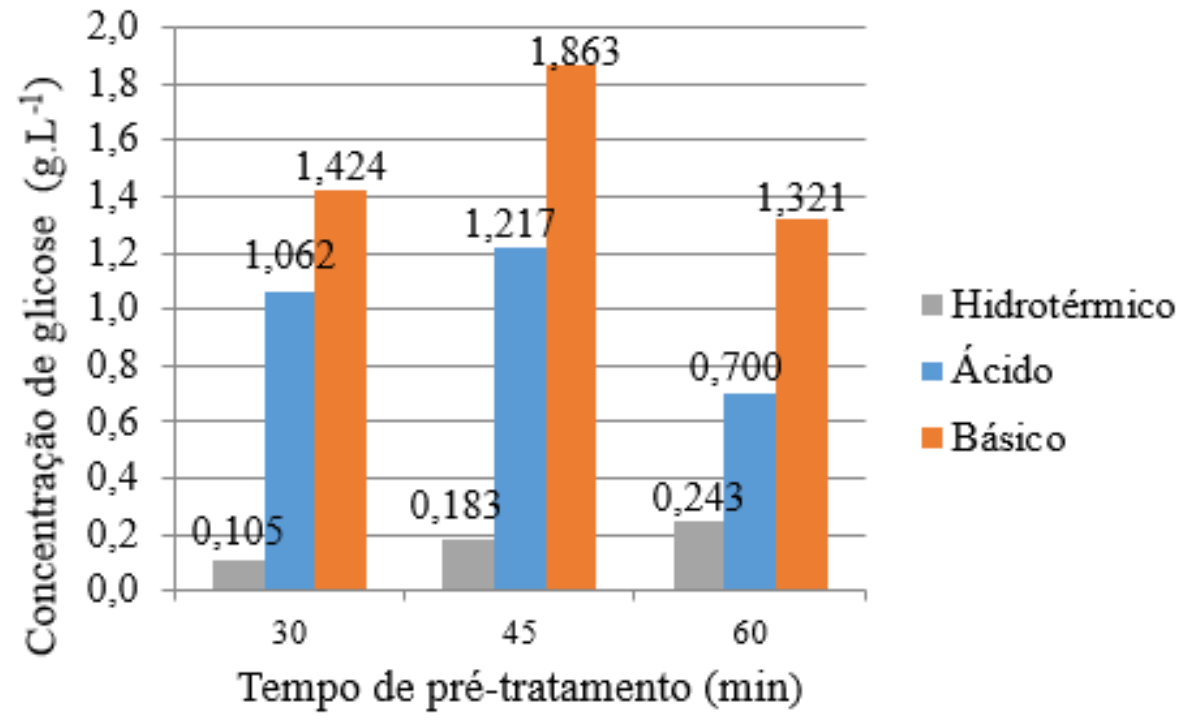

Para melhor visualização dos resultados e rendimentos, foi realizada também uma hidrólise da biomassa sem pré-tratamento, obtendo o valor de concentração de açúcares redutores igual a 0,519 g.L. $\mathrm{L}^{-1}$ (0,186 de absorbância).

Com base na literatura, foi possível comparar e verificar que os valores obtidos nos experimentos foram consideravelmente baixos, sendo assim pode-se afirmar que os prétratamentos não foram eficientes, tendo como o melhor pré-tratamento o alcalino.

Sukumaran et al (2009) também realizaram uma comparação entre os pré-tratamentos alcalino e ácido, a partir disso verificaram que o pré-tratamento alcalino apresentou maior rendimento em açúcares fermentescíveis.

Portanto compreendeu-se que hidróxido de sódio favorece a deslignificação, de acordo com Chang et al (2002) o principal efeito do pré-tratamento com o hidróxido é a remoção da lignina presente na biomassa, facilitando a reatividade dos polissacarídeos restantes.

Observou-se que após a hidrólise ácida os valores de concentração de glicose não apresentaram muita mudança, sendo o maior aumento de $35,78 \%$ no pré-tratamento de 45 minutos com $\mathrm{NaOH} 4 \%$. As possíveis explicações para esse ocorrido são a inalteração da morfologia da biomassa; degradação de carboidratos; formação de subprodutos (furfural, HMF, ácido acético, entre outros); presença de fibras cristalinas na celulose; presença de resíduos de lignina e hemicelulose. Esses aspectos podem resultar na redução de eficiência no processo de hidrolise (PIETROBON, 2008).

Segundo Millett; Baker e Satter (1976), para que ocorra a reação de hidrólise nesse processo as duas regiões da celulose, amorfa e cristalina devem ser rompidas. Condições mais leves são adequadas para regiões amorfas, e para regiões cristalinas são necessários processos drásticos. 


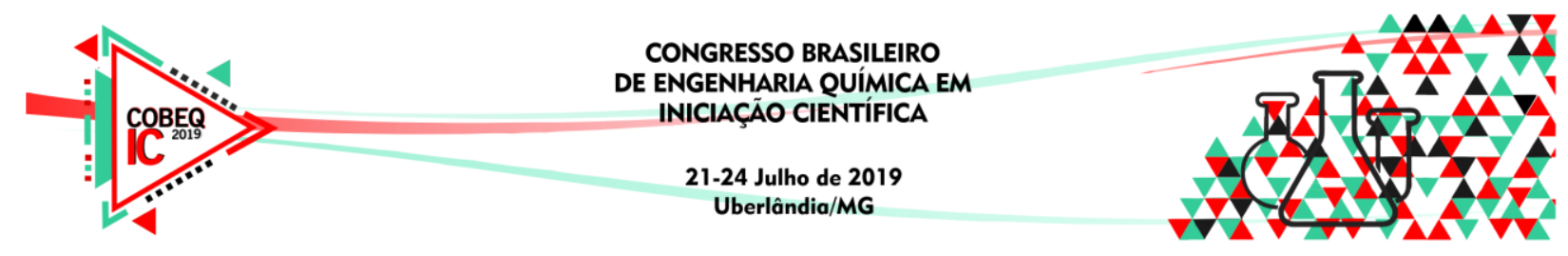

Uma outra hipótese para a hidrólise não apresentar valores consideráveis é a degradação de açúcares fermentescíveis, devido à elevada concentração do ácido empregado nessa etapa.

\section{CONCLUSÃO}

Obteve-se como melhor resultado o pré-tratamento alcalino com concentração de $4 \%$ e tempo de 45 minutos, apresentando um valor de concentração de açúcares redutores de 1,863 g.L.L após a hidrólise ácida.

Compreende-se que o desafio foi converter a parte cristalina em celulose, pois mesmo utilizando ácido concentrado nos experimentos desse trabalho, vinculado à temperatura e pressão requeridas, a hidrólise não apresentou valores de concentração de açúcares redutores desejáveis, concluindo que a celulose cristalina leva um tempo maior para ser convertida.

Esse trabalho não é uma pesquisa conclusiva, sugerindo para os seguintes estudantes aumentar o tempo, temperatura e pressão de hidrólise, na intenção de analisar se assim a região cristalina da celulose é capaz de ser convertida, ou então mudar a concentração do ácido usado na hidrólise para um ácido diluído, pois por ter usado um ácido concentrado pode ter ocorrido a degradação de carboidratos.

Para ter a confirmação das hipóteses, seria interessante realizar uma caracterização do hidrolisado por meio de análise em cromatógrafo, já que essa análise indicaria os produtos ou subprodutos formados após a hidrólise.

\section{REFERÊNCIAS}

CHANDEL, A.K.; CHANDRASEKHAR, G.; RADHIKA, K. et al. Bioconversion of pentose sugar sinto etanol; A review and future derections. Biotechnology and Molecular Biology Review, v. 6, n.1, p.8-20, 2011

CHANG C-C, YANG M-H, WEN H-M AND CHERN J-C. Estimation of total flavonoid content in propolis by two complementary colorimetric methods. J Food Drug Anal 10: 178-182, 2002.

MILlet, M. A., BAKER, A. J., SETTER, L. D. Physical and chemical pretreatments for enhancing cellulose sac-charification. Biotechnol and Bioeng. Symp. No. 6, p. 125-153. John Wiley e Sons, Inc. 1976.

OGEDA, T.; PETRI, D. Hidrólise enzimática de biomassa . 7. ed. Instituto de Química, Universidade de São Paulo, Av. Prof. Lineu Prestes, 748, 05508-900 São Paulo - SP, Brasil: Quim. Nova, 2010. 1549-1558 2010. p. v. 33. Disponível em: <http://producao.usp.br/handle/BDPI/12290>. Acesso em: 01 ago. 2018.

PIETROBON, C. V. Hidrólise do bagaço de cana-de-açúcar pré-tratado com ácido e álcali utilizando enzimas microbianas comerciais. Piracicaba, 2008. Dissertação (Mestrado). 